\title{
New Improved Method for Injection of Acrylic Resin
}

\author{
By \\ Yoshiyuki Taniguchi, Yoshikuni Ohta and Shigeru Tajiri \\ (Department of Anatomy, Osaka Dental College, Osaka)
}

\section{Preface}

So far, various kinds of material have been used, such as celluloidaceton, low-fusible metal, lamp-black and cinnaber for injecting into blood vessels or other sinus organs. These materials are injected into the cavity like ventricle of brain, blood vessels, ducts etc., for the purpose of cubically observating the forms of organs or the interrelation between them under microscope. or with naked eye.

J. K. Narat J. A. Loef and M. Narat (1936), W. O. Puckett. C.P. Neumann (1940) used vinilyte, recently A. A. Liebow (1947) used too, which is plastics (co-polymer of vinyl acetate and vinyl chloride) for the injection into vascular system of lung and respiratory tree. B. B. Karmrin . C.A. Swinyard (1950) injected the acrylic resin for dental use into auditory organ and sinus paranasales. Nagata (1950) also used dental acrylic resin for the injection into vessels of lung and liver, but this is only modification of technique of dental application. The peculiar property of the acrylic resin has not been appeared on the specimen, for that reason, we can observe only a conceptive structure of organs.

Consequently, on the base of high molecular chemistry, we made many improvement on the technique and method by Nagata and Swinyard. We have succeeded in producing polymetacrylic which is appropriate for injecting materials for. anatomical study. We also accomplished in making plastic corrosion specimens which facilitate the microscopical observation. And morever, the resin-injected tissue or organ could be made into permanent histological section by celloidin. embedding. 
The dental acrylic resin is easy to obtain and handy to use. It is composed of liquid which is metacrylic methyl ester $\mathrm{CH}_{2} \mathrm{CH}_{2}>\mathrm{C}-\mathrm{COOCH}_{3}$ (monomer), and powder which is polymetacrylate (polymer). In the methods prescribed by Swinyard and Nagata, the reaction between monomer and polymer is imperfect, so that the finished specimens show no material differences from that of old celluloid specimens. It seems that the grains of dental resin are so large that it may block up the fine vessels and ducts.

However, the polymerization of the injecting material for the purpose of anatomical research must be done at low temperature further more, the grains should be very fine, or the colloid-like solution is rather recommendable.

\section{Materials}

First of all, it is regulated the market acrylic resin to be suitable for injection.

Monomer : Monomer holds about 3/10000 hydroquinone to check polymerization. In order to accelerate the polymerization and to lower the polymerizing temperature, we distilled it thereby the hydroquinone is removed. (metacrylic methyl ester......boiling point $\left.100.3^{\circ} \mathrm{C}\right)$

Polymer: The most important fact is that the polymer must have adequate molecular weight as the injecting materials. Fine powder of polymer which possesses proper molecular weight is made from monomer, and when both are mixed, the mixture must be colloid ......sol-like solution which is suitable for injection. To above distilled monomer, add the definite medium, then snow-like polymer is obtained after polymerization. This polymer is pulverized in the mortor and shifted through $250-300$ mesh. Thus we obtained very fine powder.......we call it "special fine grain". This grains have diameter 5-10-40 microns and can be injected into extremely small vessels and ducts. (molecular weight 91500)

Colloidal solution: Even to use the special fine grain happens to be unsatisfactory. It is absolutely necessary to raise the degree of viscidity of the mixture of polymer and monomer for the following reasons, volatilization of monomer before the completion of polymerization, and permeation of monomer into surrounding tissue should be checked. Shrinkage of resin should be held to least 
extent. We made colloid (sol-like) solution of monomer and polymer. The method is as following: Monomer and polymer is mixed in rate of 1 to $6-8$ and $1 \%$ of benzoyl peroxide $\mathrm{C}_{6} \mathrm{H}_{5} \mathrm{CO}$ : OO.CO $\cdot \mathrm{C}_{6} \mathrm{H}_{5}$ (B.P.O.) to monomer is added as a medium. The mixture is put into a large mouth bottle and stoppered. For first several hours, the mixture is stirred up every 30 minutes, in order to keep the mixture in milkwhite condition, then leave it for about 72 hours. The mixture gradually assume transparent colloidal state. Microscopical examination of the colloid reveals no powderly state. This is called "sol-like solution" from now on. If it is not instant used, keep in a dark and cool place or in a ice-box, and to prevent its hardening, add proper amount of monomer, which hold $1 \%$ of B.P.O., to the solution once in a week, by doing that it will be kept in good condition for two weeks.

Plasticizer: Although the acrylic resin has pretty plasticity, the fine branches of specimen are easily breakable. To increase the plasticity of resin, dibutyl phthalate $\mathrm{C}_{6} \mathrm{H}_{4}\left(\mathrm{COOC}_{4} \mathrm{H}_{9}\right)_{2}$ is added to the injecting materials.

Colouring: For the pigmentation, oilred (Liebow), oilyellow (Liebow) prussian-blue and crimson lake are used. They are soluble in monomer as well as in oil. Dyestuffs and painting colours are insoluble in monomer, consequently, homogeneous colour can not be obtained. The red resin injected into vessels should not be discoloured or faded by using alcohol or ether in the process of making section specimen, so it is desirable to use crimson lake (red). For the distant fine branches of vessels, it is better to add much colouring materials, as the colour has tendency to faint at distance.

Radio-opaque medium: For the x-ray examination of the specimen, it should be added $0.2-0.5 \%$ of lead chromate $\mathrm{PbCrO}_{4}$ (Liebow) or bismuth compounds to the monomer.

\section{Technical Method}

\section{A. Preparation of injection material}

Injection materials should be the one the conforms to organs or parts to be injected. There are two methods of material. One method is for general cases that employed suitable to inject into very fine vessels and distant parts, and when a large quantity is required in injection. 
The other is only used when the point of injection-syringe can easily be inserted into the vessels or ducts, and small amount of material is needed and suitable when the temperature is under $25^{\circ} \mathrm{C}$.

(a) 1st method. (Two steps method)

Take proper amonut of sol-like solution in the shell, and to this add following in order :

1. Dibutyl phthalate............30-35\%

2. Dimethyl aniline ........... 1\%

3. Colouring matter ............proper amount.

Stir up the mixture well, if the mixture is too viscid, it is diluted by adding the dilution (monomer 100, dibutyl phthalate 30-35, dimethyl aniline 1). First, small amount of this mixture is injected into the finest peripheries of vessels, then to the rest, add special fine grain (holding $1 \%$ of B.P.O.) of $1 / 4-1 / 5$ volume of rest mixture and well and gently stir up. The mixture is drawn into syringe and point upward and expel the air before injection. Thus, into larger vessels, the mixture holded special fine grain is injected. Otherwise, the shrinkage of the material is large. Two steps method is advisable in case of observing the finest peripheral tissue as arterio-venous anastomosis.

(b) 2nd method.

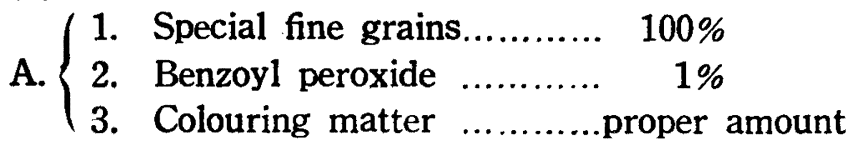

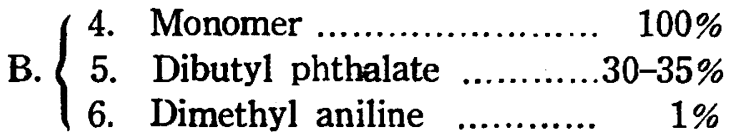

Put the mixture $\mathbf{A}$ in a deep shell, pounding it gently on the desk, drop the mixture $B$ into it until the polymer is amply saturate with mixture $B$ and the whole mixture becomes thick viscid condition. Then stir the mixture up quickly with a glass rod, drawn into syringe, after the exclusion of air, and injected instantly. As this material polymerizes for very short time, when temperature is under $25^{\circ} \mathrm{C}$, if over ten minutes passed before the injection, the hardening begins within the syringe and injection is almost impossible.

\section{B. Technique of injection.}

1. Injection: Conform the point of syringe to the vessele or ducts that to be injected and fasten both by tieing with cotton thread, the injection should be done slowly and gradually, holding the continuous pressure. 
2. Heating: The organ is covered with wet cloth. Injected organ is placed in its normal state or may be spread in accordance with some need. The injected organ is now put into drier which is regulated $45-50^{\circ} \mathrm{C}$.

In the first method, $45-50^{\circ} \mathrm{C}$ for 1 hour, or leave alone in a warm room for 3-4 hours.

In the second method, $45-50^{\circ} \mathrm{C}$ for 20 minutes, or leave alone in a warm room for 1-2 hours.

3. Digestion of surrounding tissues: The injected organ is soaked in either one of following solution.

1. $15-20 \% \mathrm{NaOH}$ or $\mathrm{KOH}$

2. Concentrated hydrochrolic acid.

In case of the injected material is not added plasticizer, the $10 \%$ of above solution is warmed to $50^{\circ} \mathrm{C}$ and soak in it for several hours.

4. Washing.

5. Dissecting the organ without digesting: For the example, in case, which is injected for carotid arteries of both sides for the purpose of studying the arteries of face, gum, teeth, with relation to other organ, tissue, the specimen is soaked in $5 \%$ of formalin.

6. Section of the resin-injected tissue for permanent specimen : Fixing fluid-formalin is the best as it does not dissolve acrylic resin. $\mathrm{By}$ the usual methods, it is embedded in celloidin, and then general or specific staining, and clearing, mounting are done after dehydration. For the clearing, bergamot oil is used, the other may dissolve acrylic resin, so avoid using.

C. Other precautions.

1. The dissected organ should be injected as soon as possible.

2. In preparing materials, the measurement of medium must be collect.

3. In case of injection into auditory organ, injected through glass tube erected on the organ. (Swinyard used metal funnel). In case of ventricle of brain, we elected rubber tube on the end of it and injected through the rubber tube.

4. In digesting soft tissues, if warmed over $55^{\circ} \mathrm{C}$, the digestion is quickened, but the specimen will be discontoured due to the thermoplasticity of dibutyl phthalate. 


\section{Summary and Conception}

Hitherto, various substances like celluloid-aceton, Wood's metal, Mellot's metal or other low.fusible metal were used for injection into vascular system and cavities. With the recent development of high molecular chemistry, acrylic resin is applied in region of anatomy as injection material.

J. K. Narat (1936), W.O. Puckett (1940) and A. A. Liebow (1947) used vinilyte as injection material. This is copolymer of vinyl acetate and vinyl chloride. This is injected in form aceton solution of $10-15 \%$, and left as it is at room temperature for $24-48$ hours. The shrinkage after hardening is considerably large, to compensate this, the filler was added.

B. B. Karmrin -C. A. Sw in yard (1950), Nagata (1950) used dental acrylic resin as injecting material. They used the mixture of monomer and polymer in rate of $2: 1$ or $4: 1$, and the mixture is left as it is until it becomes muddy. In this state, the periphery of individual grain dissolves and presents the homogenious appearance as whole, but the each grain is not dissolved. If such a mixture is injected, some of monomer diffuse or permeate into surrounding tissues. In consequence, perfect polymerization could not be obtained. If such specimens 'are examined under microscope, individual grains are seen in form of chain of beads. Such type of the specimen is not normal, and is dynamically frail. To decrease the shrinkage of vinilyte, Liebow added silica gel or diatomaceous earth as the filler in vinilyte. Upon the plasticity of vinilyte, it surpasses the acrylic resin.

Investigating the question of shrinkage, we concluded that is not so serious. By raising the viscidity of monomer and adding $25 \%$ of fine grain to it after polymerizing, the shrinkage can be controlled to its minimum extent. In measuring the shrinkage, we found that it is $0.6 \%$ in first method, and $0.4 \%$ in second method, even on the injected specimen not over $0.8 \%$.

The branches of vessles as fine as $8-10$ microns are possible to be injected. But it is difficult to inject into vessels whose walls are weak like veins or able to be injected as small branches as pigments can. But the resin does not easily effuse to surrounding parts, even if it does, the effusion is confined to small area, and those appeared on surface can be easily removed after hardened.

The plasticity can be regulated by the amount of dibutyl phthalate, 
but not reaches to the degree of plasticity vinilyte possesses.

Observation is done with naked eye, but for fine parts, magnifying glass or microscope may be necessary. The specimen not digested sorrounding soft tissues is kept in formalin solution. Afterwards, if needed it can be dissected out by tracing the coloured vessels, moreover will not be broken owing to its plasticity,

In making permanent histological specimen from the resin-injected tissue, the hardened resin in the blocks of tissue is made soft by dipping in alcohol and can be cut with microtome knife. When we should study the any vascular system, histological corrosion specimens are made, and on the other, section specimens which may help in studying are made.

Even this improved resin is not yet perfect in many points. The time of polymerization shortens over $70^{\circ} \mathrm{C}$, but small amount of white substances appear on finished specimen. This white substances are to be considered as saponified stuff produced by the fat of tissue with alkali used in digestion. This can neither be removed mechanically nor chemically. It is also found such white substances on the specimen polymerized at low temperature, but this can easily be removed by washing. It is inevitable to find some fine air bubbles in some large branches of vessels, because the pressure can not be exerted during polymerization.

Catalysts are used in order that the polymerization is possible at low temperature. In case dimethyl aniline is used as a catalyst, the resin is discoloured into light brown after mixing or polymerizing. Also diethyl ethanol amine, tri-iso-amyl amine or para-toluen sulfinic acid are used as catalysts, they don't discolour the material, but the polymerization at the peripheral finest branches are not perfect. Therefore, dimethyl aniline and B.P.O. are used again as catalysts, they don't discolour the material and the polymerization is complete.

We are to investigate the acrylic resin excluded above defects, and to find injecting method conformed to various animals and organs.

\section{Conclusion}

1. Succeeded in making fine special grain polymer from monomer, suitable for injection with a definite medium and definite polymerizing temperature.

2. Succeeded in making sol-like solution by mixing monomer and polymer in rate of $6: 1$, and stirring and leaving as it is for 72 hours. 
3. Specimen is made by mixing special grain and sol-like solution in rate of $1: 4$ in volume. To this mixture, it is added B.P.O. $1 \%$, dimethyl aniline $1 \%$ and then heating 1 hour, temperature $50^{\circ} \mathrm{C}$ after injection.

4. For the small specimen, the mixture is made by special fine grain, and $1 \%$ of B.P.O., with monomer added $1 \%$ of dimethyl aniline. Heating 20 minutes at $50^{\circ} \mathrm{C}$, or leave alone in warm room until poly. merizing.

5. Still more, as plasticizer, dibutyl phthalate $30-35 \%$ is added to the injecting resin, accordingly the fine parts of specimen is not apt to break.

6. To colour the acrylic resin, oilred and oilyellow (Liebow), prussianblue are used. And for section specimen, crimson lake (red) surely is used.

7. Not only the specimen whose tissues are digested, but the specimen is soaked in the fixed solution, and then the vessels or parts can be dissected out.

8. On the other hand, the resin-injected tissue can be made into permanent histological specimen by embedding in celloidin.

9. With our methods, injection is possible in such small vessels 5 microns at distant parts.

The authors wish to express our gratitude to Mr. K. Yoshida, Osaka Industrial Laboratory, Dr. K. Sakurai who gave us kind instructions for making the materials suitable for the injection.

\section{Literature Cited}

1) Imoto, M. Chemistry of synthetic high molecule. 1948, 1st edition, Tokyo, 34-61. -in Japanese-.

2) Karmrin, B.B., and Swinyard, C.A. The use of dental acrylic in the preparation of pressure injection casts of the auditory apparatus and paranasal sinuses. Anat. Rec., 1950, 107, 181-186.

3) Liebow, A.A., Hales, M. R., Lindskog. G.E. and Bloomer, W.E. Plastic demonstrations of pulmonary pathology. J. Tech. Methods, 1947, 27, 116-129.

4) Nagata, J. Application of synthetic resin in anatomical study. Sougou Igaku, 1950, $7,30-31$. -in Japanese-.

5) Narat, J.K., Loef, J.A., and Narat, M. On preparation of multicoloured corrosion specimens. Anat. Rec., 1936, 64, 155-160.

6) Puckett, W.O. and Neumann, C.P. Vinilyte resin in the preparation of corrosions of anatomical specimens. Anat. Rec. $1940,78,10 \mathbf{j}-108$.

7) Taniyama, T. and Iwai, N. Industry of acrylic resin and styrol resin. 1950, 1st edition. Tokyo, 26-86 and 211-219. -in Japanese--

8) Yoshida, K. Manufacture and application of vinyl chrolide resin. 1950, 1st edition, Osaka, 83-92. -in Japanese- 


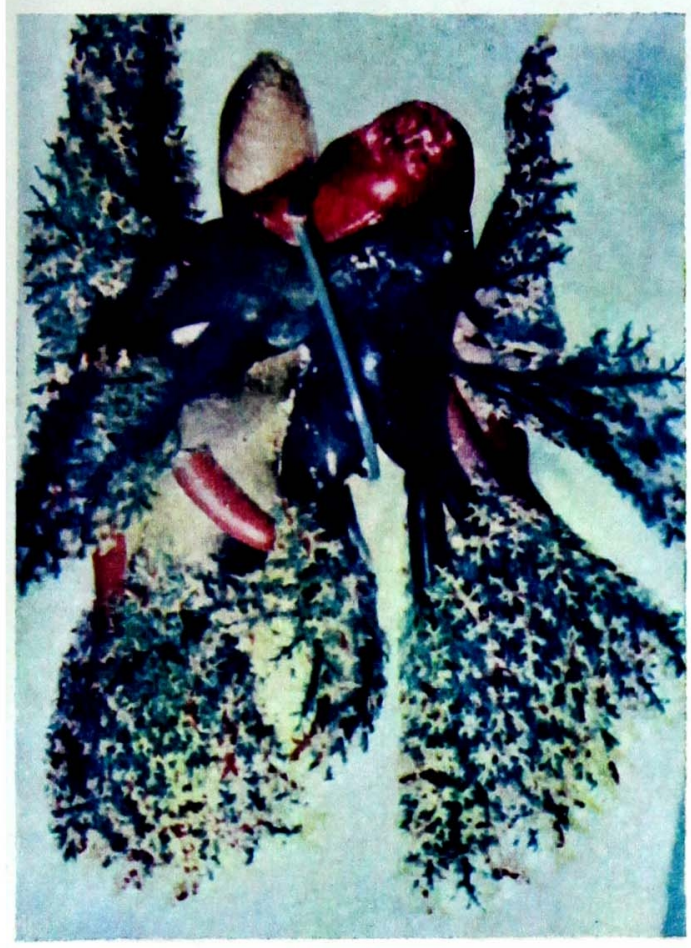

Fig. 1

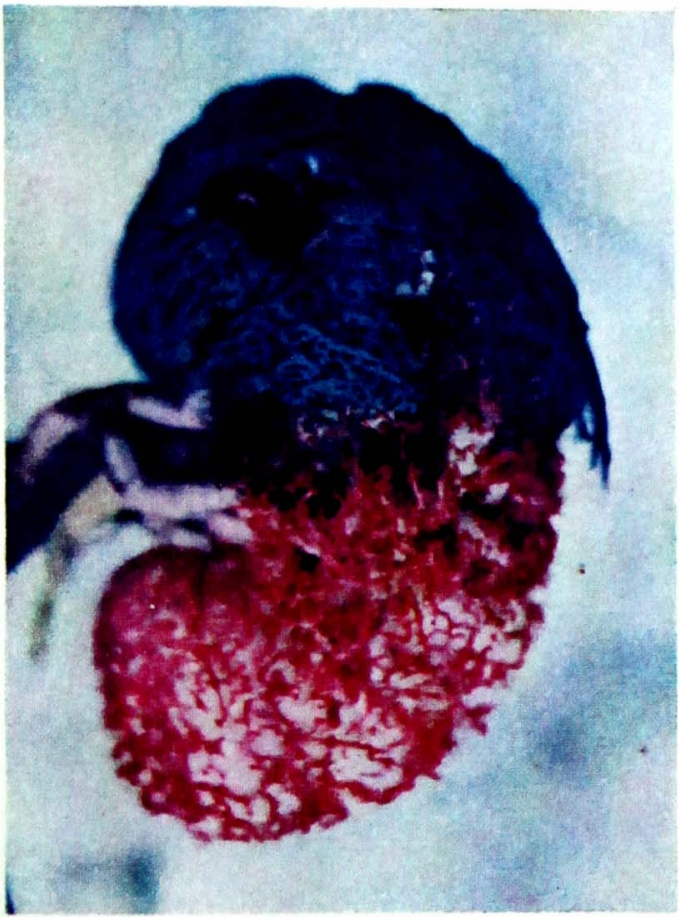

Fig. 3

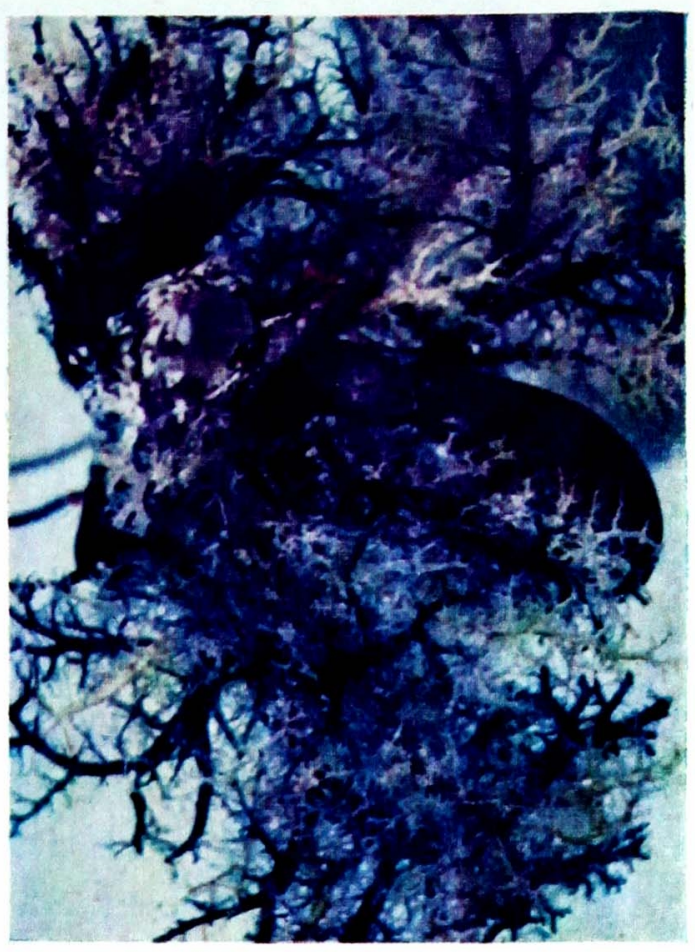

Fig. 2

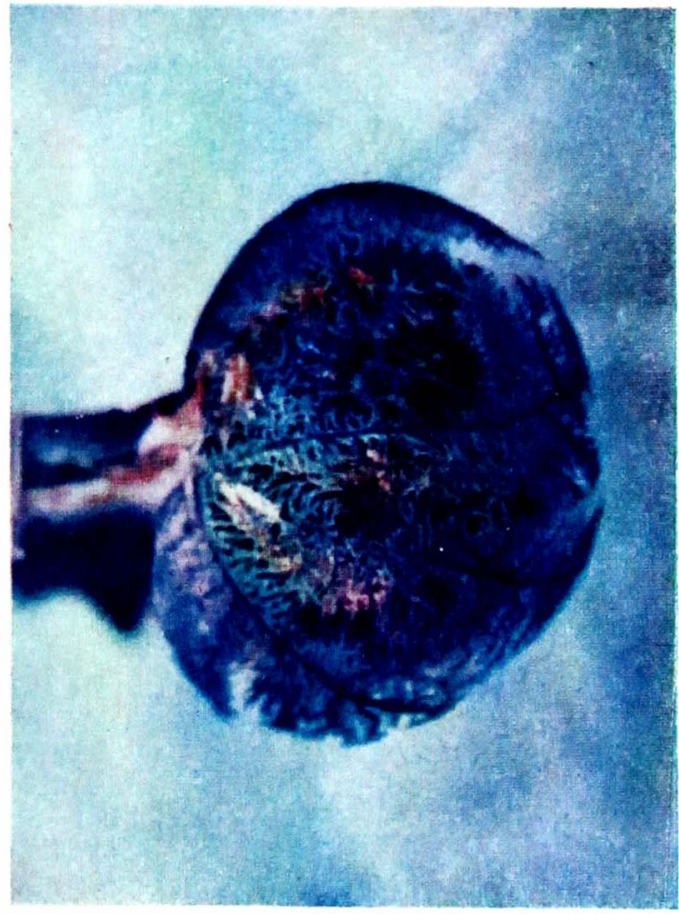

Fig. 4 


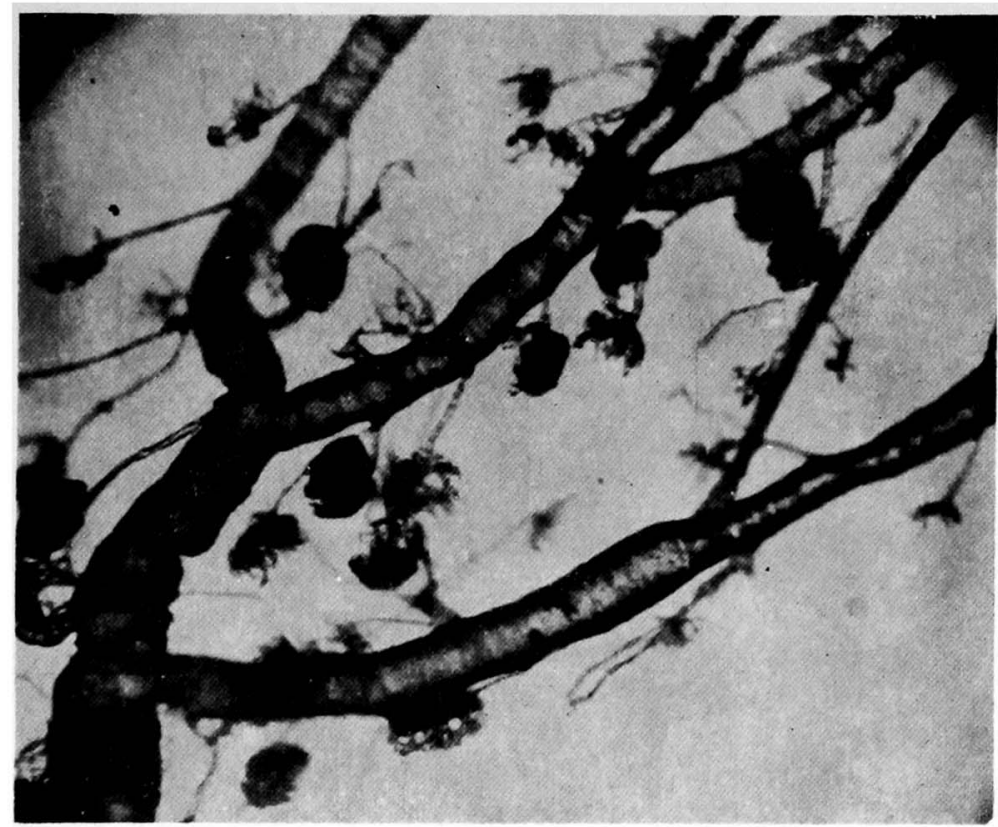

Fig, 5

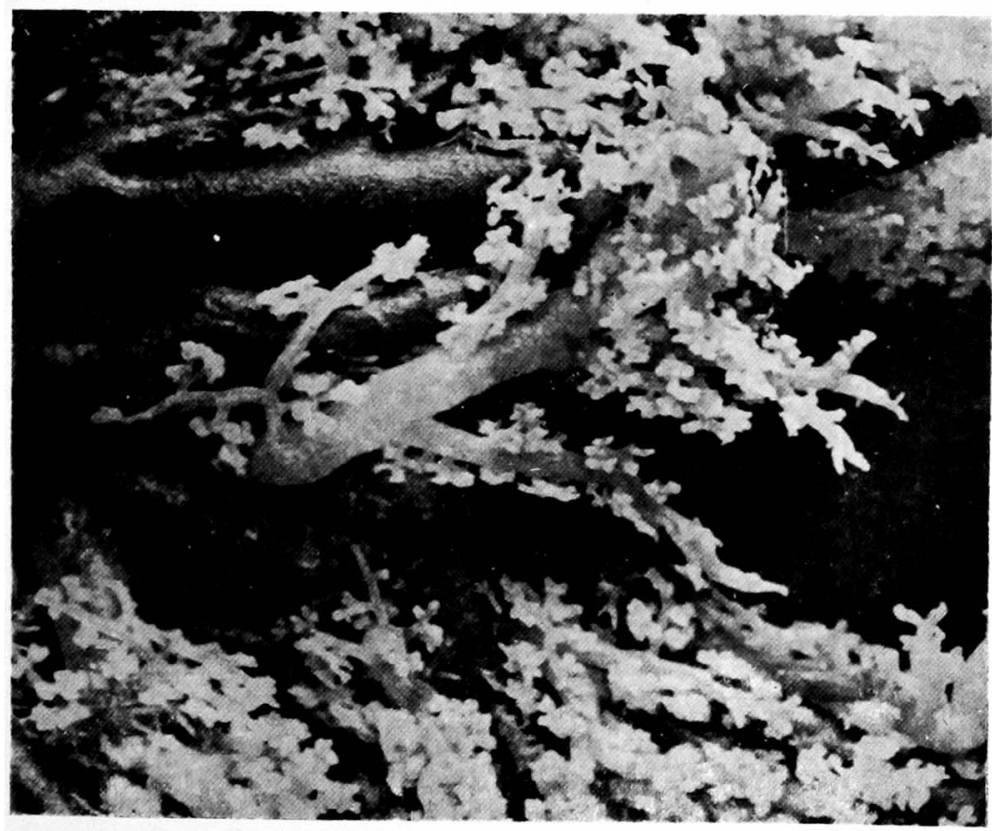

Fig. 6 


\section{Explanation of Figures}

Fig. 1. Lung of dog. $\times 0.8$

Yellow........... Trachea, bronchi and bronchuli.

Red ...............Pulmonary artery.

Blue ..............Pulmonary veins.

Every vessel has been injected into the finest of about $0.3 \mathrm{~mm}$.

Fig. 2. Liver of cat. (View of visceral surface) $\times 1.1$

Dark yellow elongated pear-shape..... gallbladder.

Red Hepatic artery proper.

Blue ............... Hepatic vein.

White ............Portal vein.

Every vessel has been injected into the finest of about $0.3 \mathrm{~mm}$.

Fig. 3. Kidney of dog. $\times 1.7$

Red .............. Renal artery.

Blue ............. Renal vein-injected into cranial half, stellate veins clearly exhibited.

Yellow Ureter.

Fig. 4. Kidney of cat. $\times 1.7$

Red Renal artery.

Blue ............. Renal vein-radiating from hilum of kidney right under the capsule, this differs from that of dog.

Fig. 5. Specimen of the renal artery of a dog. $\times 47$

Microscopic examination of a part of the injected renal artery. Shown clearly the glomeruli, arteriola afferens and efferens.

Fig. 6. Specimen of lung of a rabbit. $\times 3.5$

Injected into pulmonary artery, pulmonary veins and trachea. In this photograph, trachea injected with yellow resin which appears white, the forms of alveoli well shown. Pulmonary veins injected with blue resin which appears dark. 